\title{
The Role of Mental Imagery in Obsessive-Compulsive Disorder: An Explorative Study
}

\author{
Shrayasi Roy ${ }^{1}$, Sreemoyee Tarafder ${ }^{2}$, Rupam Banerjee ${ }^{3}$ \\ ${ }^{1}$ Research Scholar, Department of Psychology, West Bengal State University, Barasat. \\ ${ }^{2}$ Assistant Professor, Department of Psychology, West Bengal State University, Barasat. \\ ${ }^{3}$ State Aided College Teacher, Department of Psychology, Sarojini Naidu College. \\ Corresponding author: Shrayasi Roy \\ Email: roy96shrays@gmail.com
}

\begin{abstract}
Background: The present study aimed to investigate how mental imagery affects the manifestation of symptoms among people with OCD, considering its impact on symptom severity.

Methodology: For the said purpose, we compared people with OCD $(n=30)$ with a clinical control group (people suffering from Schizophrenia; $(n=30)$ and community control group $(n=30)$. Yale Brown Obsessive Compulsive Scale (assess symptom severity of OCD), Spontaneous Use of Imagery Scale (spontaneity of imagery), Vividness of Visual Imagery Questionnaire (vividness of imagery) along with Mental Clock Task (ability to generate images), Change Detection Task (maintenance of imagery), Match to Sample Task (image inspection), Mental Rotation Task (image manipulation-transformation), Ambiguous Figure Task (image restructuring) and Image Combination Task (mental synthesis) were used in the study.

Results: The result suggests that there is a difference in terms of the spontaneous use of mental imagery in daily life among the three groups. Regression analysis showed that the Image Generation and Image Manipulation-Transformation capacity plays a role in the manifestation or maintenance of Obsessive and Compulsive symptoms in OCD. Both the factors independently predict the symptom severity of Obsessive Compulsive disorder, but not in Schizophrenia.
\end{abstract}

Keywords: Obsessive-Compulsive Disorder, Schizophrenia, Mental Imagery, Cognitive Tasks

(Paper received $-9^{\text {th }}$ March 2021, Peer review completed $-6^{\text {th }}$ May 2021, Accepted $-9^{\text {th }}$ July 2021)

\section{INTRODUCTION}

Obsessive-Compulsive Disorder (OCD) is characterized by clinically significant obsessions, compulsions or both. Obsessions are disturbing thoughts, impulses, images that seem to dominate a person's consciousness. Compulsions are frequent and rigid behaviors or mental acts that people feel they must perform in order to impede or alleviate anxiety [1]. Contemporary Cognitive-Behavioral theories of OCD suggest that it arises from certain dysfunctional beliefs and attitudes that are significant factors, not just for the etiology, but also in the maintenance of the symptoms [2-4]. One aspect of obsessive-compulsive disorders which seems enormously suitable for empirical study is mental imagery. Mental imagery is the efficiency to reactivate and manipulate modality appropriate mental representations in the absence of sensory stimulation or overt motor action, and this ability can be associated with the subjective experience of perceiving or acting within one's mental world [5].

The cognitive stages of mental imagery were derived from a computational theory of imagery by Kosslyn [6-8]. Kosslyn theorized the stages of mental imagery as- (i) Image Generation, (ii) Image Maintenance, (iii) Image Inspection, (iv) Image Manipulation-Transformation-Image Restructuring and (v) Mental Synthesis. The aim of Kosslyn's theory was to establish a clear understanding of cognitive systems and processes which 
are essential in order to express the patterns of action associated with the mental images [9]. Several clinical studies have investigated the cognitive stages of mental imagery across different disorders [10-14].

Except for a few studies [15] there is a dearth of serious efforts to study imagery occurring in the context of intrusive cognitions among the non-clinical and pathological population. According to Borkovec et al. [16], the role of mental imagery seems to be important in the process of worrying and is an activity which reflects an outcome of stress. From Horowitz's [17] experiments too it has been seen that through a dramatic increase of imagery intrusions, stress can more easily activate the imagery mode - not just in the visual mode, but also under circumstances where the stress experience did not particularly include visual stimulation [18-19]. It is pertinent to mention here that Borkovec's claims were not substantiated by empirical findings [20]. Although most patients with OCD readily acknowledge the presence of imagery in the obsessive compulsive experiences, it has not been measured objectively. Therefore, the need was felt to empirically observe the role of mental imagery and its cognitive stages in OCD, Schizophrenia and Community Control.

Schizophrenia was chosen as the clinical control group as review of previous studies has suggested that there is a significant role of mental imagery in the symptom formation of Schizophrenia [21-24]. However, researchers have focused only on hallucinations - because in the absence of an accurate sensory stimulation, hallucination consists of perceptible experiences. Mental imagery also has perceptual characteristics and that may occur in the absence of accurate sensory stimuli. The difference is that mental images occur under the control of the subject [7] but the hallucinations are not within the control of the individual [8]. Mintz and Alpert [26] mentioned that individuals who experience hallucinations also have vivid images and poor ability to differentiate real perception from imagery. Owing to this failure of the reality monitoring system represented by hallucinations, inwardly generated perceptions are erroneously attributed to an exotic source [26].

The present study attempts to empirically explore the role of mental imagery in obsessive-compulsive disorder, in comparison with Schizophrenia and Community Controls. The hypothesis of the study claims that vividness of mental imagery will be higher in OCD and Schizophrenia as compared to community controls. There may be a definite role of vividness and spontaneous use of mental imagery in OCD, Schizophrenia and Control Group. Assessment of mental imagery will be done not just through imagery questionnaires, but also substantiated with performance on neurocognitive tasks for Image Generation, Image Maintenance, Image Inspection, Image Transformation-Manipulation and Mental Synthesis. The present study attempts to compare people with obsessive compulsive disorder (OCD) with persons with Schizophrenia (SCZ) and with Control Group (CG) drawn from the community.

The aims and objectives of the present study are:

- To assess whether there is any significant difference in terms of vividness of visual imagery as assessed by Vividness of Visual Imagery Questionnaire among OCD, SCZ and CG.

- To determine whether there is any significant difference in spontaneous use of imagery in daily life as assessed by Spontaneous Use of Imagery Scale among OCD, SCZ and CG.

- To determine whether there is any significant difference in cognitive aspects of mental imagery, as assessed by Mental Clock Task, Change Detection Task, Match to Sample Task, Mental Rotation Task, Ambiguous Figure Task and Image Combination Task among OCD, SCZ and CG.

- To determine the impact of mental imagery along with cognitive aspects of mental imagery among Clinical and Control Groups.

\section{METHODOLOGY}

\section{Sample}

Based on Purposive Sampling, three groups of participants were included - OCD Group ( $\mathrm{n}=30$ ), Schizophrenia Group $(n=30)$ and Control Group $(n=30)$. The Clinical Group consisted of patients who met the diagnostic criteria of OCD and Schizophrenia without any co morbidity as per DSM-V. The clinical participants were selected from psychiatric services of Calcutta National Medical College and HospitalCalcutta Pavlov Hospital, Kolkata, India. The participants were within 45 years of age and the educational 
qualification of the participants was at least till class ten. People, who did not meet the criteria of OCD or Schizophrenia as per DSM-V, were excluded. Clinical patients, with a diagnosis of OCD or Schizophrenia with co-morbidity of any other psycho-social disability, people aged more than 45 years, and patients in remission were excluded. The Control group was matched according to the age ( +2 years), sex and educational qualification with the Study Groups. People with a history of any kind of psycho-social disability and people aged more than 45 years, have been excluded.

The standardized tools that were used in present study were- Yale-Brown Obsessive and Compulsive Scale [27], Vividness of Visual Imagery Questionnaire [28] and Spontaneous Use of Imagery Scale [29].

In keeping with the cognitive stages of mental imagery explained by Kosslyn [30], cognitive tasks were chosen in consultation with two cognitive psychologists in order to ensure that the task selection was pertaining to Kosslyn's stages. Wherever possible, computerized versions of the tasks were used through PEBL. Tasks such as Mental Clock Task (MC), Change Detection Task (CD), Match to Sample Task (MTS), Mental Rotation Task (Rot), Interpretation of Ambiguous Figure Task (AFT) and Image Combination Task (ICT).

\begin{tabular}{|l|l|}
\hline Cognitive Stages & Tasks Corresponding to Kosslyn's Stages of Mental Imagery \\
\hline Image Generation & Mental Clock Task [31] Verbal Task \\
\hline Image Maintenance & Change Detection Task [32] PEBL Version \\
\hline Image Inspection & Match to Sample Task [33-34] PEBL Version \\
\hline $\begin{array}{l}\text { Image Transformation- } \\
\text { Manipulation \& } \\
\text { Image Restructuring }\end{array}$ & Mental Rotation Task [35] PEBL Version \\
\cline { 2 - 2 } & Interpretation of Ambiguous Figure Task [36] Visual-Verbal Task \\
\hline Mental Synthesis & Image Combination Task [37] Verbal Task \\
\hline
\end{tabular}

\section{Procedure}

On the basis of the inclusion and exclusion criteria, participants were selected. It was a case-control study. A form containing the details of socio demographic information was filled by the participants. After filling the socio demographic details, Yale Brown Obsessive Compulsive Scale was administered. Mental Clock Task, Interpretation of Ambiguous Figure Task, Image Combination Task and the computerized version of Change Detection Task, Match to Sample Task, Mental Rotation Task were administered. This was followed by Vividness of Visual Imagery Questionnaire and Spontaneous Use of Imagery Scale. The tests were done in one session with the duration of 45-60 minutes. The order of tests was not kept constant for the participants to avoid order effect. After obtaining data from 90 participants of the three groups, the statistical analysis of the data was done using Statistical Package for Social Sciences (SPSS) Version 20.

\section{STATISTICAL ANALYSIS}

One way ANOVA was carried out to assess the differences between OCD, SCZ and CG groups. Tukey HSD Post-Hoc Analysis was carried out to do the pair wise comparison among three groups. Pearson correlation was carried out to determine the relationship between obsessive symptoms and severity with domains of mental imagery among the three groups. Stepwise Linear Regression was carried out in the three groups separately to determine potential explanatory variables and draw conclusions about the impact of Imagery along with the cognitive tasks on symptom severity of Obsession and Compulsion.

\section{RESULTS AND DISCUSSION}

\section{Mean differences: OCD, SCZ and CG}

The result shows (Table:1) that there is a significant difference between groups as determined by One Way ANOVA in the tasks of image generation (MC-R) $(\mathrm{F}=7.895, \mathrm{p}=.001)$; time taken for image generation (MCTime $)(F=25.903, p=.000)$, image maintenance $(C D-R)(F=3.146, p=.048)$, image manipulation- 
Table 1: Group differences among the domains and Pair wise comparison of three groups

\begin{tabular}{|c|c|c|c|c|c|c|c|c|c|c|}
\hline \multicolumn{7}{|c|}{ Mean Differences: One Way ANOVA } & \multicolumn{4}{|c|}{ Pair wise Comparison } \\
\hline Domain & & $\begin{array}{l}\text { Sum of } \\
\text { Squares }\end{array}$ & df & $\begin{array}{l}\text { Mean } \\
\text { Square }\end{array}$ & $\mathbf{F}$ & Sig. & Domain & $\begin{array}{c}\text { Group } \\
\text { Compared }\end{array}$ & $\begin{array}{c}\text { Mean } \\
\text { Difference }\end{array}$ & Sig. \\
\hline \multirow[t]{3}{*}{ VVIQ-EO } & $\begin{array}{c}\text { Between } \\
\text { Groups }\end{array}$ & 29.60 & 2 & 14.80 & 0.19 & 0.82 & \multirow[t]{3}{*}{ VVIQ-EO } & OCD-SCZ & -0.60 & 0.96 \\
\hline & $\begin{array}{l}\text { Within } \\
\text { Groups }\end{array}$ & 6604.80 & 87 & 75.91 & & & & OCD-CG & -.1 .40 & 0.80 \\
\hline & Total & 6634.40 & 89 & & & & & SCZ-CG & -0.80 & 0.93 \\
\hline \multirow[t]{3}{*}{ VVIQ-EC } & $\begin{array}{c}\text { Between } \\
\text { Groups }\end{array}$ & 198.02 & 2 & 99.01 & .960 & 0.38 & \multirow[t]{3}{*}{ VVIQ-EC } & OCD-SCZ & 2.50 & 0.60 \\
\hline & $\begin{array}{l}\text { Within } \\
\text { Groups }\end{array}$ & 8975.76 & 87 & 103.17 & & & & OCD-CG & -.1 .03 & 0.91 \\
\hline & Total & 9173.78 & 89 & & & & & SCZ-CG & -3.53 & 0.37 \\
\hline \multirow[t]{3}{*}{ SUIS } & $\begin{array}{c}\text { Between } \\
\text { Groups }\end{array}$ & 518.02 & 2 & 259.01 & 4.08 & 0.02 & \multirow[t]{3}{*}{ SUIS } & OCD-SCZ & $-5.83^{*}$ & 0.01 \\
\hline & $\begin{array}{l}\text { Within } \\
\text { Groups }\end{array}$ & 5513.93 & 87 & 63.37 & & & & OCD-CG & -2.30 & 0.50 \\
\hline & Total & 6031.95 & 89 & & & & & SCZ-CG & 3.53 & 0.20 \\
\hline \multirow[t]{3}{*}{ MC-R } & $\begin{array}{c}\text { Between } \\
\text { Groups }\end{array}$ & 112.46 & 2 & 56.23 & 7.89 & 0.00 & \multirow[t]{3}{*}{ MC- R } & OCD-SCZ & $.2 .53^{*}$ & 0.00 \\
\hline & $\begin{array}{l}\text { Within } \\
\text { Groups }\end{array}$ & 619.63 & 87 & 7.12 & & & & OCD-CG & 0.36 & 0.85 \\
\hline & Total & 732.10 & 89 & & & & & SCZ-CG & $-2.16^{*}$ & 0.00 \\
\hline \multirow[t]{3}{*}{ MC-Time } & $\begin{array}{c}\text { Between } \\
\text { Groups }\end{array}$ & 137651.66 & 2 & 68825.83 & 25.90 & 0.00 & \multirow[t]{3}{*}{ MC-Time } & OCD-SCZ & $-79.33^{*}$ & 0.00 \\
\hline & $\begin{array}{l}\text { Within } \\
\text { Groups }\end{array}$ & 231167.93 & 87 & 2657.10 & & & & OCD-CG & 6.83 & 0.86 \\
\hline & Total & 368819.60 & 89 & & & & & SCZ-CG & $86.16^{*}$ & 0.00 \\
\hline \multirow[t]{3}{*}{ CD-R } & $\begin{array}{c}\text { Between } \\
\text { Groups }\end{array}$ & 33.75 & 2 & 16.87 & 3.146 & 0.04 & \multirow[t]{3}{*}{ CD-R } & OCD-SCZ & 0.73 & 0.44 \\
\hline & $\begin{array}{l}\text { Within } \\
\text { Groups }\end{array}$ & 466.73 & 87 & 5.36 & & & & OCD-CG & -0.76 & 0.40 \\
\hline & Total & 500.48 & 89 & & & & & SCZ-CG & $-1.50^{*}$ & 0.03 \\
\hline \multirow[t]{3}{*}{ CD-Time } & $\begin{array}{c}\text { Between } \\
\text { Groups }\end{array}$ & $\begin{array}{c}3440467951 \\
.26\end{array}$ & 2 & $\begin{array}{c}17202339 \\
75.63\end{array}$ & 0.09 & 0.91 & \multirow[t]{3}{*}{ CD-Time } & OCD-SCZ & -11411.93 & 0.94 \\
\hline & $\begin{array}{l}\text { Within } \\
\text { Groups }\end{array}$ & $\begin{array}{c}1668099546 \\
966.83\end{array}$ & 87 & $\begin{array}{c}19173558 \\
011.11\end{array}$ & & & & OCD-CG & -14328.56 & 0.91 \\
\hline & Total & $\begin{array}{c}1671540014 \\
918.10\end{array}$ & 89 & & & & & SCZ-CG & -2916.63 & 0.99 \\
\hline \multirow[t]{3}{*}{ MTS-R } & $\begin{array}{c}\text { Between } \\
\text { Groups }\end{array}$ & 32.46 & 2 & 16.23 & 2.22 & 0.11 & \multirow[t]{3}{*}{ MTS-R } & OCD-SCZ & -0.83 & 0.46 \\
\hline & $\begin{array}{l}\text { Within } \\
\text { Groups }\end{array}$ & 635.53 & 87 & 7.30 & & & & OCD-CG & -1.46 & 0.09 \\
\hline & Total & 668.00 & 89 & & & & & SCZ-CG & -0.63 & 0.63 \\
\hline \multirow[t]{3}{*}{ ROT-R } & $\begin{array}{c}\text { Between } \\
\text { Groups }\end{array}$ & 1032.42 & 2 & 516.21 & 8.91 & 0.00 & \multirow[t]{3}{*}{ Rot-R } & OCD-SCZ & $8.23^{*}$ & 0.00 \\
\hline & $\begin{array}{l}\text { Within } \\
\text { Groups }\end{array}$ & 5038.86 & 87 & 57.91 & & & & OCD-CG & $5.00^{*}$ & 0.03 \\
\hline & Total & 6071.28 & 89 & & & & & SCZ-CG & -3.23 & 0.23 \\
\hline ROT-Time & $\begin{array}{c}\text { Between } \\
\text { Groups }\end{array}$ & $\begin{array}{c}2382971242 \\
3.08\end{array}$ & 2 & $\begin{array}{c}11914856 \\
211.54\end{array}$ & 1.39 & 0.25 & Rot-Time & OCD-SCZ & -18603.93 & 0.71 \\
\hline
\end{tabular}




\begin{tabular}{|c|c|c|c|c|c|c|c|c|c|c|}
\hline & $\begin{array}{l}\text { Within } \\
\text { Groups }\end{array}$ & $\begin{array}{c}7450163983 \\
29.23\end{array}$ & 87 & $\begin{array}{c}85634068 \\
77.34\end{array}$ & & & & OCD-CG & 21225.16 & 0.64 \\
\hline & Total & $\begin{array}{c}7688461107 \\
52.32\end{array}$ & 89 & & & & & SCZ-CG & 39829.10 & 0.22 \\
\hline \multirow[t]{3}{*}{ AFT-R } & $\begin{array}{c}\text { Between } \\
\text { Groups }\end{array}$ & 402.42 & 2 & 201.21 & 16.17 & 0.00 & \multirow[t]{3}{*}{ AFT-R } & OCD-SCZ & $3.33^{*}$ & 0.00 \\
\hline & $\begin{array}{l}\text { Within } \\
\text { Groups }\end{array}$ & 1082.46 & 87 & 12.44 & & & & OCD-CG & -1.76 & 0.13 \\
\hline & Total & 1484.88 & 89 & & & & & SCZ-CG & $-5.10^{*}$ & 0.00 \\
\hline \multirow[t]{3}{*}{ ICT-R } & $\begin{array}{l}\text { Between } \\
\text { Groups }\end{array}$ & 30.68 & 2 & 15.34 & 8.67 & 0.00 & \multirow[t]{3}{*}{ ICT-R } & OCD-SCZ & $1.16^{*}$ & 0.00 \\
\hline & $\begin{array}{l}\text { Within } \\
\text { Groups }\end{array}$ & 153.93 & 87 & 1.76 & & & & OCD-CG & -0.13 & 0.92 \\
\hline & Total & 184.62 & 89 & & & & & SCZ-CG & $-1.30^{*}$ & 0.00 \\
\hline \multirow[t]{3}{*}{ YBOCS-O } & $\begin{array}{l}\text { Between } \\
\text { Groups }\end{array}$ & 1712.60 & 2 & 856.30 & 220.21 & 0.00 & \multirow[t]{3}{*}{$\begin{array}{c}\text { YBOCS- } \\
\text { O }\end{array}$} & OCD-SCZ & $9.40^{*}$ & 0.00 \\
\hline & $\begin{array}{l}\text { Within } \\
\text { Groups }\end{array}$ & 338.30 & 87 & 3.88 & & & & OCD-CG & 9.10* & 0.00 \\
\hline & Total & 2050.90 & 89 & & & & & SCZ-CG & -0.30 & 0.82 \\
\hline \multirow[t]{3}{*}{ YBOCS-C } & $\begin{array}{c}\text { Between } \\
\text { Groups }\end{array}$ & 1480.82 & 2 & 740.41 & 207.74 & 0.00 & \multirow[t]{3}{*}{$\begin{array}{c}\text { YBOCS- } \\
\text { C }\end{array}$} & OCD-SCZ & $9.03^{*}$ & 0.00 \\
\hline & $\begin{array}{l}\text { Within } \\
\text { Groups }\end{array}$ & 310.06 & 87 & 3.56 & & & & OCD-CG & $8.10^{*}$ & 0.00 \\
\hline & Total & 1790.88 & 89 & & & & & SCZ-CG & -0.93 & 0.14 \\
\hline \multirow[t]{3}{*}{ YBOCS-T } & $\begin{array}{l}\text { Between } \\
\text { Groups }\end{array}$ & 6397.80 & 2 & 3198.90 & 258.00 & 0.00 & \multirow[t]{3}{*}{ YBOCS-T } & OCD-SCZ & $18.50^{*}$ & 0.00 \\
\hline & $\begin{array}{l}\text { Within } \\
\text { Groups }\end{array}$ & 1078.70 & 87 & 12.39 & & & & OCD-CG & $17.20^{*}$ & 0.00 \\
\hline & Total & 7476.50 & 89 & & & & & SCZ-CG & -0.13 & 0.33 \\
\hline
\end{tabular}

transformation (Rot-R) $(\mathrm{F}=8.913, \mathrm{p}=.000)$, in other domains of image manipulation-transformation such as (ICT) and (AFT) respectively $(\mathrm{F}=8.672, \mathrm{p}=.000) ;(\mathrm{F}=16.172, \mathrm{p}=.000)$. Statistically significant difference was found in the tasks of spontaneous use of imagery (SUIS) $(F=4.087, p=.020)$ and obviously in the measures of symptom severity of obsession-compulsion (YBOCS-T) $(F=258.000, p=.000)$ along with in obsessive (YBOCS-O) $(\mathrm{F}=220.213, \mathrm{p}=.000)$ and in compulsive (YBOCS-C) $(\mathrm{F}=207.748, \mathrm{p}=.000)$ symptoms distinctively.

A Tukey post hoc test results (Table:1) revealed that OCD group obtained significantly higher score in the tasks of image generation (MC-R), image manipulation-transformation (Rot-R) with other domains of image manipulation (ICT-R, AFT-R) and the symptom severity (YBOCS-T) of the disorder as compared to SCZ and CG. OCD group obtained statistically significant lower scores in the tasks of spontaneous use of imagery (SUIS), time taken for image generation (MC-Time) as compared to SCZ. The post hoc test also showed that SCZ obtained statistically significant higher scores in the task of spontaneous use of imagery in daily life (SUIS) as compared to OCD and CG. The lower scores were obtained in the task of image generation (MC-R), in the domains of image manipulation-transformation (ICT-R, AFT-R) as compared to $\mathrm{OCD}$ and CG. The CG obtained a significantly higher score in the task of image maintenance (CD-R) as compared to SCZ which is determined by post hoc test.

\section{Correlation: OCD, SCZ and CG}

A significant positive correlation (Table:2) was found between symptom severity (YBOCS) and time taken for image generation (MC-Time), YBOCS and time taken for image manipulation-transformation (RotTime) and negative correlation was found between YBOCS and image maintenance (CD-Response) in the 
OCD group. A significant positive correlation was found between symptom severity (YBOCS) and image maintenance (CD-Response) in the SCZ group. In CG, unlike the OCD and clinical control group, there was no correlation observed between the aspects of mental imagery and YBOCS (symptom severity). Refer to Table 2 for correlation between cognitive stages of mental imagery and obsessive compulsive symptoms among the three groups.

Table 2: Correlations between cognitive stages of mental imagery and obsessive compulsive symptoms among three groups

\begin{tabular}{|c|c|c|c|c|c|c|}
\hline & \multicolumn{2}{|c|}{ OCD } & \multicolumn{2}{|c|}{ SCZ } & \multicolumn{2}{|c|}{ CG } \\
\hline Domain & $\begin{array}{l}\text { Correlated } \\
\text { with }\end{array}$ & $\begin{array}{l}\text { Correlation } \\
\text { Coefficient }\end{array}$ & $\begin{array}{l}\text { Correlated } \\
\text { with }\end{array}$ & $\begin{array}{l}\text { Correlation } \\
\text { Coefficient }\end{array}$ & $\begin{array}{l}\text { Correlated } \\
\text { with }\end{array}$ & $\begin{array}{l}\text { Correlation } \\
\text { Coefficient }\end{array}$ \\
\hline \multirow[t]{5}{*}{ YBOCS-T } & MC-R & $0.41^{*}$ & CD-R & $0.52^{* *}$ & YBOCS-O & $0.81^{* *}$ \\
\hline & CD-R & $-0.38^{*}$ & YBOCS-O & $0.96^{* *}$ & \multirow[t]{4}{*}{ YBOCS-C } & \multirow[t]{4}{*}{$0.72^{* *}$} \\
\hline & Rot-Time & $0.43^{*}$ & \multirow[t]{3}{*}{ YBOCS-C } & \multirow[t]{3}{*}{$0.85^{* *}$} & & \\
\hline & YBOCS-O & $0.95^{\text {** }}$ & & & & \\
\hline & YBOCS-C & 0.97 ** & & & & \\
\hline
\end{tabular}

\section{Regression Analysis}

From results obtained by regression analysis (Refer to Table 3) it can be seen that image manipulationtransformation (Rot-Time) explains $16.4 \%$ variance of YBOCS-Total score (Adj $\mathrm{R}^{2}=0.164, \mathrm{~F}=6.700$, standardized coefficient: $\beta=0.439, p=0.001$ ) and image manipulation-transformation (Rot-Time) in conjunction with image generation (MC-Time) explains $33.5 \%$ variance(Adj $\mathrm{R}^{2}=0.335 ; \mathrm{F}=8.303$, standardized coefficient: $\beta=-0.441, p=0.002$ ) of YBOCS- Total score in OCD Group. The result was found in the SCZ group with image maintenance (CD-Response) explaining $25.0 \%$ proportion of variance of YBOCS-Total Score (Adj $R^{2}=0.250 ; F=10.668$, standardized coefficient: $\beta=0.525, p=0.003$ ).

Table 3: Regression Analysis among OCD, SCZ \& CG

\begin{tabular}{|c|c|c|c|c|c|c|c|c|c|}
\hline $\begin{array}{c}\text { Dependent } \\
\text { Variable }\end{array}$ & Predictors & \multicolumn{2}{|c|}{ OCD Group } & Predictors & \multicolumn{2}{|c|}{ SCZ Group } & \multirow[t]{2}{*}{ Predictors } & \multicolumn{2}{|c|}{$\begin{array}{c}\text { Community Control } \\
\text { Group }\end{array}$} \\
\hline \multirow[t]{3}{*}{$\begin{array}{l}\text { YBOCS- } \\
\text { Total }\end{array}$} & & $\begin{array}{c}\text { Adjusted } \\
\mathbf{R}^{2}\end{array}$ & $\begin{array}{c}\text { Std. } \\
\text { Error of } \\
\text { Estimate }\end{array}$ & & $\begin{array}{c}\text { Adjusted } \\
\mathbf{R}^{2}\end{array}$ & $\begin{array}{c}\text { Std. } \\
\text { Error of } \\
\text { Estimate }\end{array}$ & & $\begin{array}{l}\text { Adjusted } \\
\mathbf{R}^{2}\end{array}$ & $\begin{array}{l}\text { Std. } \\
\text { Error of } \\
\text { Estimate }\end{array}$ \\
\hline & Rot-Time & 0.16 & 4.41 & \multirow[t]{2}{*}{ CD-R } & \multirow[t]{2}{*}{0.25} & \multirow[t]{2}{*}{2.57} & \multirow[t]{2}{*}{ NONE } & \multirow[t]{2}{*}{ - } & \multirow[t]{2}{*}{-} \\
\hline & $\begin{array}{l}\text { Rot Time } \\
\text { \& MC- } \\
\text { Time }\end{array}$ & 0.33 & 3.93 & & & & & & \\
\hline
\end{tabular}

\section{DISCUSSION}

\section{Group differences and pair-wise comparison among OCD, SCZ \& CG in terms Mental Imagery}

From the overall result of the tasks of mental imagery it can be seen that SCZ indulges significantly more in spontaneous use of imagery than OCD Group. It can be explained by saying that in SCZ, the ability to generate and spontaneously use imagery plays a role in the manifestation or maintenance of psychotic symptoms [38] particularly in hallucinations [39]. Additionally, it can be seen that the participants of SCZ showed significantly less image maintenance (CD-R), image restructuring (AFT-R) and mental synthesis 
(ICT-R) than the CG. In contrast, spontaneous use of imagery is not evident in OCD group and the present findings support previous research cited by Fink [40]. However, in terms of image generation (MC-R), image manipulation-transformation (Rot-R) and image restructuring (AFT-R) and mental synthesis (ICT-R), the OCD group scores higher than any other groups. It may be interpreted that when an intrusive anxietyprovoking or distressing image pops up in their mind, it is maintained by the people with OCD through negative attention. Since these thoughts or images receive full attentional priority, it is extremely difficult for persons with OCD to ignore it [41] which perhaps prompts them to transform and manipulate the image. Owing to the mechanism of mental control paradox [42] the harder they try to control the intrusive image or thought, the more difficult it becomes for them. So they keep trying to transform and manipulate the mental image. Present finding of greater image generation and image manipulation-transformation corresponds with this mechanism used by people with OCD.

\section{The association between mental imagery \& symptom severity among Clinical Groups (OCD, SCZ)}

The finding sheds light on the fact that although there is no mean difference on imagery domains across the three groups (as obtained from One Way ANOVA) except SUIS, there are some underlying dynamics between imagery and symptom severity of obsessions and compulsions. It can be further seen that the relationship between image generation, image manipulation-transformation and symptom severity (for both obsessive and compulsive symptoms) is only seen in the OCD group. Our findings corroborate with the work of Pearson [30] that in the OCD group, there is a deficit in actively maintaining the images which have been generated. As mentioned earlier, people with OCD may interpret the image through manipulating or transforming it. The resultant distorted version of the image in the mind may lead them to indulge in compulsive behavior [30]. Previous research has supported the assumption [6], that the generation and manipulation-transformations of images are evident in obsession and compulsion which includes shift or blink transformation. In shift transformation, original images are held and then transformed gradually, whereas, in blink transformation the original image is substituted by a new one. These strategies are used by the people with OCD in order to replace the offending obsessive and compulsive images [43].

In the present study, YBOCS was used not to specifically comment upon the position of SCZ in terms of symptom severity of YBOCS but to show their comparative standing viz a viz OCD. This brings specificity to the finding regarding the OCD Group. The present study clearly shows that there is a presence of spontaneous use of imagery in daily life among the people with schizophrenia. Previous studies [25] have shown that the imageries are involuntary in case of schizophrenia because of their inability to differentiate between real perceptions and imagery [26]. So the habitual and spontaneous use of imagery is actually maintaining a subjective reality which is not imagery per se. Our study substantiates the work of Bocker et al [44] that there is a lack of deliberate control of imagery as it contests with the perception of subjective reality. It is maintained as perceptible experiences in the form of externally based perceptions which is basically a misinterpretation of inwardly generated mental images and this leads to the symptom formation.

\section{The impact of mental imagery among OCD, SCZ and CG}

When the impact of the domains pertaining to mental imagery was seen on obsessive compulsive symptoms severity, image generation and image manipulation-transformation emerged as a predictor in OCD and image maintenance in SCZ. No such finding was there for community controls. The finding in OCD may be associated with Rachman's [45] assumption that an unwanted image is generated and also perceived to have negative personal significance, it is done through catastrophic misinterpretation which is likely to turn into a recurrent obsessive image. The images can be reshaped or replaced through benign images through manipulation or transformation which leads to maintenance of the distorted images and an urge is felt to perform compulsive acts [46].

The finding in SCZ can be explained by noting that the internally generated images do not decay rapidly in Schizophrenia [47-48] and are therefore maintained. The impairment in reality monitoring [49] results in maintenance of subjective reality which is different from imagery [44] as mentioned earlier. 


\section{Limitations}

The primary limitation of the study is that it is a cross sectional, small sample study. Another limitation of the study is that all the participants were not drug naive, and drugs could have certain effects on the performance of cognitive tasks.

\section{CONCLUSIONS}

The Image Generation and Image Manipulation-Transformation capacity plays a significant role in the manifestation or maintenance of Obsessive and Compulsive symptoms in OCD. Both the factors independently predict the symptom severity of the disorder.

\section{REFERENCES}

1. Whiteside SP, Brown AM, Abramowitz JS. Five-day intensive treatment for adolescent OCD: A case series. J Anxiety Disord 2008;22(3):495-504.

2. Clark DA. Cognitive-behavioral therapy for OCD. Guilford Press; 2006.

3. Frost RO, Steketee G, Williams L. Compulsive buying, compulsive hoarding, and obsessive-compulsive disorder. Behav Ther 2002;33(2):201-14.

4. Salkovskis PM, Wroe AL, Gledhill A, Morrison N, Forrester E, Richards C, Reynolds M, Thorpe S. Responsibility attitudes and interpretations are characteristic of obsessive compulsive disorder. Behav Res Ther 2000;38(4):347-72.

5. Schendan HE, Searl MM, Melrose RJ, Stern CE. An FMRI study of the role of the medial temporal lobe in implicit and explicit sequence learning. Neuron 2003;37(6):1013-25.

6. Kosslyn SM. Image and mind. Harvard University Press; 1980.

7. Kosslyn SM, Alpert NM, Thompson WL, Chabris CF, Rauch SL, Anderson AK. Identifying objects seen from different viewpoints A PET investigation. Brain 1994;117(5):1055-71.

8. Kosslyn SM, Thompson WL, Ganis G. The case for mental imagery. Oxford University Press; 2006.

9. Kosslyn SM, Kosslyn SM. Graph design for the eye and mind. OUP USA; 2006.

10. Fresco DM, Frankel AN, Mennin DS, Turk CL, Heimberg RG. Distinct and overlapping features of rumination and worry: The relationship of cognitive production to negative affective states. Cogn Ther Res 2002;26(2):179-88.

11. Holmes EA, Geddes JR, Colom F, Goodwin GM. Mental imagery as an emotional amplifier: Application to bipolar disorder. Behav Res Ther 2008;46(12):1251-8.

12. Hagenaars MA, Holmes EA. Mental imagery in psychopathology: Another step; Editorial for the special issue of journal of experimental psychopathology. J Experiment Psychopathol 2012;3(2):121-6.

13. Amir N, Najmi S, Morrison AS. Image generation in individuals with generalized social phobia. Cogn Ther Res 2012;36(5):537-47.

14. Hales S, Blackwell SE, Di Simplicio M, Iyadurai L, Young K, Holmes EA. Imagery-based cognitivebehavioral assessment. Assessment in cognitive therapy 2014:69-93.

15. Rachman S. Unwanted intrusive images in obsessive compulsive disorders. J Behav Ther Experiment Psychiatry 2007;38(4):402-10.

16. Borkovec TD, Robinson E, Pruzinsky T, DePree JA. Preliminary exploration of worry: Some characteristics and processes. Behav Res Ther 1983;21(1):9-16.

17. Cougle JR, Lee HJ, Horowitz JD, Wolitzky-Taylor KB, Telch MJ. An exploration of the relationship between mental pollution and OCD symptoms. J Behav Ther Exp Psychiatry 2008;39(3):340-53.

18. Brett EA, Ostroff R. Imagery and posttraumatic stress disorder: An overview. Am J Psychiatry 1985;142(4):417-24

19. Laufer RS, Gallops MS, Frey-Wouters E. War stress and trauma: The Vietnam veteran experience. J Health Soc Behav 1984;1:65-85.

20. Hirsch CR, Hayes S, Mathews A, Perman G, Borkovec T. The extent and nature of imagery during worry and positive thinking in generalized anxiety disorder. J Abnorm Psychol 2012;121(1):238-44.

21. Chandiramani K, Varma VK. Imagery in schizophrenic patients compared with normal controls. Br J Med Psychol 1987;60(4):335-41.

22. Aleman A, Nieuwenstein MR, Böcker KB, de Haan EH. Music training and mental imagery ability. Neuropsychologia 2000;38(12):1664-8.

23. Sack AT, Van De Ven VG, Etschenberg S, Schatz D, Linden DE. Enhanced vividness of mental imagery as a trait marker of schizophrenia?. Schizophr Bull 2005;31(1):97-104.

24. Oertel V, Rotarska-Jagiela A, van de Ven V, Haenschel C, Grube M, Stangier U, Maurer K, Linden DE. Mental imagery vividness as a trait marker across the schizophrenia spectrum. Psychiatr Res 2009;167(1-2):1.

25. Bentall RP. The illusion of reality: a review and integration of psychological research on hallucinations. Psychol Bull 1990;107(1):82-6. 
26. Mintz S, Alpert M. Imagery vividness, reality testing, and schizophrenic hallucinations. J Abnorm Psychol 1972;79(3):310-20.

27. Veale D, Page N, Woodward E, Salkovskis P. Imagery Rescripting for Obsessive Compulsive Disorder: A single case experimental design in 12 cases. J Behav Ther Exp Psychiatry 2015;49:230-6.

28. Marks DF. Visual imagery differences in the recall of pictures. Br J Psychol 1973;64(1):17-24.

29. Reisberg D, Pearson DG, Kosslyn SM. Intuitions and introspections about imagery: The role of imagery experience in shaping an investigator's theoretical views. Appl Cogn Psychol 2003;17(2):147-60.

30. Pearson DG, Deeprose C, Wallace-Hadrill SM, Heyes SB, Holmes EA. Assessing mental imagery in clinical psychology: A review of imagery measures and a guiding framework. Clin Psychol Rev 2013;33(1):1-23.

31. Paivio A. Imagery, language, and semantic memory. International Journal of Psycholinguistics. 1978.

32. Luck D. A psycholinguistic approach to leader personality: Imagery of aggression, sex, and death in Lenin and Stalin. Soviet Studies 1978;30(4):491-515.

33. Skinner BF. Are theories of learning necessary?. Psychol Rev 1950;57(4):193-8.

34. Englund CE, Reeves DL, Shingledecker CA, Thorne DR, Wilson KP. Unified Tri-Service Cognitive Performance Assessment Battery (UTC-PAB). 1. Design and Specification of the Battery. NAVAL HEALTH RESEARCH CENTER SAN DIEGO CA; 1987 Feb 23.

35. Shepard RN, Metzler J. Mental rotation of three-dimensional objects. Science 1971;171(3972):701-3.

36. Chambers D, Reisberg D. Can mental images be ambiguous?. J Exp Psychol 1985;11(3):317-30.

37. Finke RA. Principles of mental imagery. The MIT Press; 1989.

38. Malcolm CP, Picchioni MM, Ellett L. Intrusive prospective imagery, posttraumatic intrusions and anxiety in schizophrenia. Psychiatr Res 2015;230(3):899-904.

39. Malcolm CP. Trauma-related processes in schizophrenia (Doctoral dissertation, University of London).

40. Fink J, Pflugradt E, Stierle C, Exner C. Changing disgust through imagery rescripting and cognitive reappraisal in contamination-based obsessive-compulsive disorder. J Anxiety Disord 2018;54:36-48.

41. Purdon C, Clark DA. Overcoming obsessive thoughts: How to gain control of your OCD. New Harbinger Publications; 2005.

42. Freeston $\mathrm{MH}$, Dugas $\mathrm{MJ}$, Ladouceur R. Thoughts, images, worry, and anxiety. Cogn Ther Res 1996;20(3):265-73.

43. de Silva P. Obsessional-compulsive imagery. Behav Res Ther 1986;24(3):333-50.

44. Aleman A, Nieuwenstein MR, Böcker KB. Mental imagery and perception in hallucination-prone individuals. J Nerv Ment Disease 2000;188(12):830-6.

45. Rachman S. Unwanted intrusive images in obsessive compulsive disorders. J Behav Ther Exp Psychiatry 2007;38(4):402-10.

46. Rachman S. Betrayal: A psychological analysis. Behav Res Ther 2010;48(4):304-11.

47. Gold AL, Shin LM, Orr SP, Carson MA, Rauch SL, Macklin ML, Lasko NB, Metzger LJ, Dougherty DD, Alpert NM, Fischman AJ. Decreased regional cerebral blood flow in medial prefrontal cortex during traumaunrelated stressful imagery in Vietnam veterans with post-traumatic stress disorder. Psychol Med 2011;41(12):2563-72.

48. Brébion G, Amador X, David A, Malaspina D, Sharif Z, Gorman JM. Positive symptomatology and sourcemonitoring failure in schizophrenia — an analysis of symptom-specific effects. Psychiatr Res 2000;95(2):11931.

49. Brébion G, Ohlsen RI, Pilowsky LS, David AS. Visual hallucinations in schizophrenia: confusion between imagination and perception. Neuropsychol 2008;22(3):383-400.

$* * * * * * * * * * * * * * * * * * * * * * * * * * * * * * * * * * * *$

Acknowledgements - We convey our heartfelt thanks to Dr. Srijit Ghosh (Psychiatrist) and Ms. Samadrita Bhattacharya (Clinical Psychologist) for referring patients from Calcutta National Medical College and Hospital - Calcutta Pavlov Hospital. We gratefully thank Debabrata Biswas Sir for his valuable comments

Conflict of Interest - Nil

Funding - Nil 